\title{
Drought and Cooler Temperatures Are Associated with Higher Nest Survival in Mountain Plovers
}

\section{La sécheresse et les températures fraîches sont associées au taux de survie des nids supérieur chez le Pluvier montagnard}

\author{
Victoria J. Dreitz $^{1,2}$, Reesa Yale Conrey ${ }^{3}$, and Susan K. Skagen ${ }^{4}$
}

\begin{abstract}
Native grasslands have been altered to a greater extent than any other biome in North America. The habitats and resources needed to support breeding performance of grassland birds endemic to prairie ecosystems are currently threatened by land management practices and impending climate change. Climate models for the Great Plains prairie region predict a future of hotter and drier summers with strong multiyear droughts and more frequent and severe precipitation events. We examined how fluctuations in weather conditions in eastern Colorado influenced nest survival of an avian species that has experienced recent population declines, the Mountain Plover (Charadrius montanus). Nest survival averaged 27.2\% over a 7-yr period $(\mathrm{n}=$ 936 nests) and declined as the breeding season progressed. Nest survival was favored by dry conditions and cooler temperatures. Projected changes in regional precipitation patterns will likely influence nest survival, with positive influences of predicted declines in summer rainfall yet negative effects of more intense rain events. The interplay of climate change and land use practices within prairie ecosystems may result in Mountain Plovers shifting their distribution, changing local abundance, and adjusting fecundity to adapt to their changing environment.
\end{abstract}

RÉSUMÉ. Les prairies naturelles ont été plus grandement modifiées que tout autre biome en Amérique du Nord. L'habitat et les ressources nécessaires pour favoriser la performance reproductrice des oiseaux de prairie endémiques de ces écosystèmes sont actuellement menacés par les pratiques de gestion des terres et les changements climatiques imminents. Les modèles climatiques pour les prairies des Grandes Plaines prévoient des étés plus chauds et plus secs, des sécheresses sévères durant plusieurs années et des évènements de précipitation plus fréquents et intenses que ce qu'on observe présentement. Nous avons examiné les effets des fluctuations des conditions météorologiques dans l'est du Colorado sur la survie des nids chez une espèce aviaire ayant subi un récent déclin des populations, le Pluvier montagnard (Charadrius montanus). Le taux de survie des nids s'élevait à $27,2 \%$ en moyenne sur une période de 7 ans $(\mathrm{n}=936$ nids $)$ et diminuait à mesure que progressait la saison de reproduction. La survie des nids était supérieure quand les conditions étaient sèches et les températures fraîches. Les changements prévus dans les tendances régionales des précipitations influenceront vraisemblablement la survie des nids : tandis que la diminution des précipitations estivales prévue entraînera un effet positif sur la survie, les évènements de précipitation plus intenses prévus auront, quant à eux, un effet négatif. L'interaction des changements climatiques et des pratiques d'utilisation des sols dans les écosystèmes de prairie amènera peut-être le Pluvier montagnard à modifier sa répartition, son abondance locale et sa fécondité pour s'adapter à l'environnement changeant.

Key Words: Charadrius montanus, climate change, Mountain Plover, nest survival, weather

\section{INTRODUCTION}

Native grasslands have been altered to a greater extent than any other biome in North America (Samson et al. 2004), resulting in the conversion of the once diverse grassland landscape into a collection of homogenous grassland fragments interspersed with agricultural fields (Lomolino et al. 2001, Brockway et al. 2002, Brennan and Kuvlesky 2005). These alterations are likely to have contributed to the

\footnotetext{
${ }^{1}$ Colorado Division of Wildlife, ${ }^{2}$ Wildlife Biology Program, College of Forestry and Conservation, University of Montana, ${ }^{3}$ under contract with the U.S. Geological Survey Fort Collins Science Center, ${ }^{4}$ U.S. Geological Survey Fort Collins Science Center
}

continental-scale declines in grassland avifauna, which have been steeper and more consistent than declines in any other avian guild over the past century (Knopf 1994).

Although direct anthropogenic changes can contribute to loss and degradation of avian habitat in the North American prairies, shifts in weather patterns also may result in changes in the condition, quality, and viability of prairie ecosystems, and thus the distribution, phenology, and reproductive output

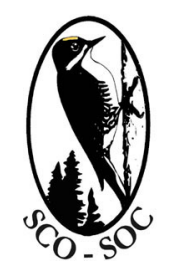

Sponsored by the Society of Canadian Ornithologists and Bird Studies Canada Parrainée par la Société des ornithologistes du Canada et Études d'oiseaux Canada

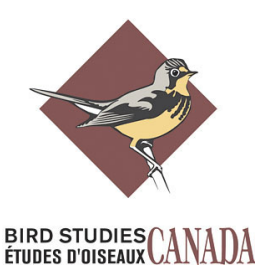


of many grassland birds. Presumably by affecting food resources, habitat structure, or predator abundance and behavior, higher levels of precipitation favor reproductive success of several grassland and shrubland passerines, such as Brewer's Sparrow (Spizella breweri), Rufous-crowned Sparrow (Aimophila ruficeps), and Lark Bunting (Calamospiza melanocorys; Rotenberry and Wiens 1989, 1991; Morrison and Bolger 2002, Skagen and Yackel Adams 2012). Precipitation, however, may not lead to higher reproductive output in the Mountain Plover (Charadrius montanus), a unique grassland species at the extreme of grassland bird habitat niches that prefers highly disturbed or exposed ground (Knopf 1996) within the prairie ecosystems of North America.

Mountain Plovers are short-distance migratory birds that breed in grasslands and recently tilled agricultural fields in interior North America from Montana to northern New Mexico and the panhandles of Oklahoma and Texas, and winter in dry plains from California to Texas with the largest concentration in the Imperial Valley, California (Knopf and Wunder 2006). During the breeding season, female plovers split their clutches between two nest sites, incubating at the second site while the males incubate at the first nest site (Knopf and Wunder 2006). Steep declines in population size have been reported for Mountain Plovers across their range since 1966, presumably stemming from loss of grassland habitats to agriculture and declining prairie dog populations. In 1999, the U.S. Fish and Wildlife Service was petitioned for 'threatened' status of the Mountain Plover, but a decision in 2003 found that listing was not warranted (USFWS 2003). Listing of the Mountain Plover as threatened was reconsidered in 2010 and the proposed listing was withdrawn (USFWS 2011). Regardless of legal conservation status, a better understanding of the factors that affect life history traits is imperative for the development of conservation strategies for this species that breeds and winters within the borders of the Great Plains region of North America.

Reproductive output is one crucial component in determining population performance of a migratory species. An element of reproductive performance, nest survival, is defined as the probability that a nest will be successful with $\geq 1$ egg hatching (precocial species) or $\geq 1$ nestling fledging (altricial species; Dinsmore et al. 2002). Nest survival of Mountain Plover, a precocial species, has been estimated across the species' breeding range, including areas in Colorado (e.g., Graul 1975, Knopf and Rupert 1996, Knopf and Wunder 2006, Mettenbrink et al. 2006, Dreitz and Knopf 2007) and Montana (e.g., Knowles et al. 1982, Knowles and Knowles 1984, Dinsmore et al. 2002), and ranges from 26\% (Knopf and Rupert 1996) to 65\% (Graul 1975). Studies examining factors influencing nest survival have found higher survival of nests attended by males rather than females (Dinsmore et al. 2002), that nest survival does not differ with land use, i.e., rangeland vs. agricultural lands (Dreitz and Knopf 2007), and is independent of the distance from anthropogenic edges (Mettenbrink et al. 2006). Dinsmore et al. (2002) examined the influence of daily weather measures on nest survival of Mountain Plovers in Montana, the northern fringe of the species' range. Their findings suggest that daily precipitation events decreased daily nest survival, i.e., the probability a nest will survive one day, but maximum daily temperature had no effect.

Colorado is considered the stronghold for Mountain Plovers, because over half of the continent's population is believed to breed in the state, particularly on the eastern plains (Kuenning and Kingery 1998). The eastern plains of Colorado is an expansive area of $>90,000 \mathrm{~km}^{2}$ of shortgrass prairie bordered by the foothills of the Rocky Mountains to the west and the state's borders to the east, north, and south. Drought is the primary ecological driver that maintains the shortgrass prairie ecosystem (Askins et al. 2007) in eastern Colorado. Annual variation in precipitation is the key mechanism influencing the function and structure of the area (Collins et al. 2008). Within-year in spatial variation in precipitation is relatively low at distances $<40 \mathrm{~km}$ and nearly equal in magnitude to annual temporal variation at distances of $120-160 \mathrm{~km}$ (Augustine 2010). The shortgrass prairie ecosystem experiences extreme weather conditions because of its location inland and east of a large mountain barrier resulting in large inter- and intra-seasonal fluctuations in weather patterns (Pielke and Doesken 2008). Climate models for this area predict a future of hotter and drier summers with strong multiyear droughts and more frequent and severe precipitation events (Matthews 2008).

We examined how seasonal and daily weather conditions influenced nest survival of Mountain Plovers across the eastern plains of Colorado during a 7 -yr period. Our objectives were to distinguish whether temperatures and precipitation levels at seasonal or daily time scales influence the outcome of nesting attempts within the core range of Mountain Plovers, and secondly, to determine what weather conditions during the breeding season favored nest survival of Mountain Plovers. Knowledge of how mountain plovers respond to shifts in weather events across their breeding area will be invaluable to inform conservation practices and management agendas in the face of impending climate change.

\section{METHODS}

\section{Study area}

The study area covered 13 counties in the eastern plains of Colorado, USA (Fig. 1) consisting of private and public lands. The eastern Colorado landscape is relatively flat, dominated by rangeland pastures vegetated by low-growing buffalograss (Buchloe dactyloides) and blue grama (Bouteloua gracilis), and grazed to varying degrees by domestic livestock, native 
ungulates, and black-tailed prairie dogs (Cynomys ludovicianus). Pastures were interspersed with patches of agricultural fields and to a lesser extent, native shrublands and riparian areas. Agricultural fields were comprised predominately of dryland crops with some irrigated crops near arid river systems.

Fig. 1. Map of study area in eastern Colorado and the weather stations that provided data. Mountain Plover (Charadrius montanus) nests were located in the shaded counties, mainly on private land. Fewer than $20 \%$ of nests were on public land located in the Pawnee National Grassland, which borders Wyoming. Nests were located near the northern and southern borders of Colorado, but none were near the eastern border with Kansas. The nearest weather stations to each nest are shown with closed black triangles. Additional stations, located east of -105.35 degrees longitude, with available data but that were not nearest to nests are shown with open triangles. Black lines represent the major highways in eastern Colorado.

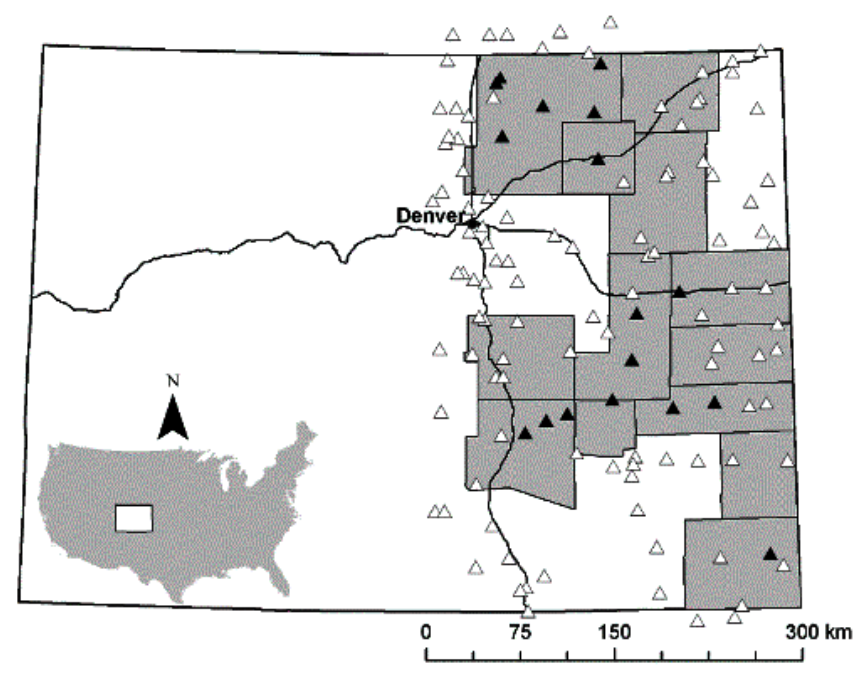

\section{Nesting monitoring}

Each year from 2001 to 2006 and in 2009, data collection began in mid-April and continued until the last nest hatched. Study plots were systematically searched for Mountain Plover nests $\geq 4$ times throughout the nesting period. We either slowly drove a motorized vehicle or walked, dependent on access requirements, across each pasture or agriculture field and periodically stopped to scan for plovers. Individual adult plovers were observed until they returned to the nest or their behavior indicated they did not have a nest, e.g., flew out of area, exhibited courting behavior, or had chicks present. We defined a nest as a structure with $\geq 1$ egg. Multiple nest structures or scrapes may be constructed within a nest site, but only one nest structure contains eggs (Knopf and Wunder 2006). We marked nests with a small flag and/or "natural" marker consisting of dried cattle droppings or agricultural vegetation.

Nests were checked every 3-12 d until the eggs hatched or failed. Mountain Plovers do not begin incubation until the clutch is complete, with the incubation period lasting $29 \mathrm{~d}$ (Dinsmore et al. 2002). Nests were considered successful if $\geq$ 1 egg hatched, regardless of the size of the clutch. If hatching was not directly observed, evidence at nests such as small eggshell fragments (Mabee 1997) and/or finding young near the nest was used to assess hatching. As with many ground nesting precocial species, the first small eggshell fragments made by the hatching young remain in the nest while the adults remove the larger fragments (Knopf and Wunder 2006). These small "pip chips" are quite visible with their contrasting bluegreen and white coloration. Nests were classified as failed when no small eggshell fragments were present in the nest, eggs were missing or broken, or the adult abandoned the nest. In 2004-2009, nests were checked more often as hatch date approached, resulting in increased accuracy of hatch date estimation.

\section{Weather variables}

We obtained daily precipitation and temperature values from the weather station closest to each nest. Stations (Fig. 1) were administered by the National Oceanic and Atmospheric Administration (NOAA; data requested from www.ncdc.noaa. gov/oa/climate/stationlocator.html), the Shortgrass Steppe Long Term Ecological Research project, and U.S. Department of Agriculture-Agricultural Research Service. If weather data in a given day were unavailable from the nearest weather station, we used data from the next nearest station. Because the timing of data collection differed among stations (00:0000:30, 06:00-08:00, or 17:00-18:00 hours), some measurements were offset by one day so that nest fate was associated with the most recent minimum temperature (early morning 05:00), maximum temperature (previous afternoon), and precipitation event (previous afternoon). The distance between weather stations and nests was $<42 \mathrm{~km}$; at these distances, spatial variation in precipitation within a year is relatively low compared with annual variation (Augustine 2010). Daily values were averaged (for temperature) or summed (for precipitation) over May-June, encompassing $90 \%$ of the nesting season, to produce seasonal values.

\section{Data analysis}

Daily nest survival (DNS), the probability that a nest will survive a single day, was calculated using the nest survival model in Program MARK, version 5.1 (White and Burnham 1999). Daily nest survival could be influenced by a large number of patterns in daily and seasonal weather conditions. To limit the number of models evaluated, we developed a set of a priori biological hypotheses and used these to choose 
Table 1. Explanatory variables used to model daily nest survival of Mountain Plovers (Charadrius montanus).

\begin{tabular}{|c|c|c|c|}
\hline \multicolumn{2}{|r|}{ Daily Variable } & \multicolumn{2}{|r|}{ Seasonal Variable } \\
\hline Variable Name & Variable Name & Variable Name & Variable Name \\
\hline \multicolumn{4}{|l|}{ Precipitation } \\
\hline Precip & daily precipitation & TotalPcp & total precipitation \\
\hline Over5mm ${ }^{\dagger}$ & day had $\geq 5 \mathrm{~mm}$ rain & Days $5 \mathrm{~mm}$ & \# days with $\geq 5 \mathrm{~mm}$ rain \\
\hline Over10 $\mathrm{mm}^{\dagger}$ & day had $\geq 10 \mathrm{~mm}$ rain & Days $10 \mathrm{~mm}$ & \# days with $\geq 10 \mathrm{~mm}$ rain \\
\hline $0 \mathrm{~mm}^{\dagger}$ & day had no rain & Days0mm & \# days with no rain \\
\hline 5DayDrought ${ }^{\dagger}$ & $5+$ consec. days $w /$ total rain $\leq 1 \mathrm{~mm}$ & & \\
\hline 7DayDrought ${ }^{\dagger}$ & $7+$ consec. days $\mathrm{w} /$ total rain $\leq 1 \mathrm{~mm}$ & & \\
\hline 10DayDrought ${ }^{\dagger}$ & $10+$ consec. days $\mathrm{w} /$ total rain $\leq 1 \mathrm{~mm}$ & & \\
\hline \multicolumn{4}{|l|}{ Temperature } \\
\hline MinTemp & daily minimum temp & AvgMin & average daily minimum temp \\
\hline MaxTemp & daily maximum temp & AvgMax & average daily maximum temp \\
\hline MeanTemp & daily mean temp & AvgMean & average daily mean temp \\
\hline TempRange & daily temp range $(\max -\min )$ & AvgRange & average daily temp range \\
\hline Over29C & day had max temp $\geq 29^{\circ} \mathrm{C}$ & Days29C & \# days with max temp $\geq 29^{\circ} \mathrm{C}$ \\
\hline Over32C $\mathrm{C}^{\dagger}$ & day had max temp $\geq 32^{\circ} \mathrm{C}$ & Days32C & \# days with $\max$ temp $\geq 32^{\circ} \mathrm{C}$ \\
\hline Over $35 \mathrm{C}^{\dagger}$ & day had max temp $\geq 35^{\circ} \mathrm{C}$ & Days35C & \# days with $\max$ temp $\geq 35^{\circ} \mathrm{C}$ \\
\hline Under0 $C^{\dagger}$ & day had $\min$ temp $\leq 0^{\circ} \mathrm{C}$ & Days0C & \# days with $\min$ temp $\leq 0^{\circ} \mathrm{C}$ \\
\hline Under $4 C^{\dagger}$ & day had $\min$ temp $\leq 4^{\circ} \mathrm{C}$ & Days4C & $\#$ days with $\min$ temp $\leq 4^{\circ} \mathrm{C}$ \\
\hline \multicolumn{4}{|l|}{ Time-in-Season } \\
\hline Time & linear trend (day $1-110)$ & & \\
\hline \multicolumn{4}{|c|}{ 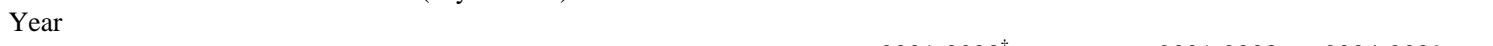 } \\
\hline & & $2001-2003^{\dagger}$ & 2001-2003 vs. $2004-2009$ \\
\hline
\end{tabular}

Seasonal weather variables were created by summing or averaging daily values for May-June of each year. For each daily weather variable, 1-day lag effects (previous day's weather) were also modeled. Droughts were defined as periods when at least 5,7 , or 10 days had passed with $\leq 1 \mathrm{~mm}$ total rainfall. Hatch dates were known with greater accuracy beginning in 2004 because nests were visited more often as hatch date approached. Quadratic effects were modeled for continuous variables when AIC -based model selection indicated at least moderate support for the main effect (Appendix 1).

${ }^{\dagger}=$ binary variable.

explanatory variables (Table 1) and guide construction of the model set (Appendix 1). The types of weather variables that we considered to have the greatest potential influence on DNS, based on the scientific literature for plovers and other grassland and shrubsteppe bird species, were daily precipitation, daily temperature, seasonal precipitation, and seasonal temperature (Rotenberry and Wiens 1989, George et al. 1992, Dinsmore et al. 2002). Within each of these four categories, we included variables such as total daily precipitation, daily maximum temperature, total precipitation during the breeding season, and average daily maximum temperature during the breeding season, respectively. Two additional climate-related variables, time-in-season and year, were also included in the model set (Table 1) because previous studies suggested their importance to DNS (Dinsmore et al. 2002, Davis 2005, Grant et al. 2005, Dreitz and Knopf 2007).

We first ran univariate models to evaluate the importance of time-in-season (linear or quadratic) and year and to identify the weather variables in each category that best explained DNS. Akaike's information criterion for small samples (AIC $)$ was used to infer support for the models (Akaike 1973, Burnham and Anderson 2002). We selected the weather variables that appeared in univariate models with $\Delta \mathrm{AIC}_{c} \leq 2$ within each weather category. If no variables met this criterion because none of them improved the model beyond a constant survival model, we selected the top two (minimum $\mathrm{AIC}_{c}$ ) variables within that weather category. We then developed additive models with the selected weather effects, time-inseason, and year (Table 1), including a maximum of one weather variable per category. We thought that threshold effects might occur for some continuous variables; for example, very low and very high temperatures might be associated with lower daily nest survival, with higher nest survival at moderate temperatures. Therefore, quadratic effects were modeled for continuous variables when $\mathrm{AIC}_{c}-$ based model selection indicated at least moderate support for the main effect (Appendix 1). If two variables were highly correlated ( $r \geq 0.7$ ), only one was included within a given model.

We calculated nest success as DNS ${ }^{\mathrm{x}}$, where $\mathrm{x}$ is the number of days of incubation (29 in Mountain Plovers) following Dinsmore et al. (2002) and Dreitz and Knopf (2007). Dates were scaled so that day 1 was the first date when a nest was found (Apr 18) during the study. In total, we considered 94 candidate models and used the logit link function to evaluate covariate effects on DNS (Appendix 1). Because nest survival data are a known fate data type, a saturated model with one parameter per day for each nest would fit the data perfectly; 
Table 2. Nest survival models for Mountain Plover (Charadrius montanus). We ran 94 models with minimum AICc $=2204.43$ for the model set. Models with weight $\geq 0.05$ are shown. All models contain an intercept.

\begin{tabular}{|c|c|c|c|c|}
\hline Model & $\Delta \mathrm{AIC}_{c}$ & $w_{i}$ & $K$ & Deviance \\
\hline Time + 10DayDrought + MaxTemp & 0 & 0.13 & 4 & 2196.43 \\
\hline Time + 10DayDrought + MaxTemp + TotalPcp & 0.13 & 0.12 & 5 & 2194.56 \\
\hline Time + 10DayDrought + MaxTemp + Days $10 \mathrm{~mm}$ & 0.96 & 0.08 & 5 & 2195.39 \\
\hline Time + Time ${ }^{2}+10$ DayDrought + LagOver35C & 1.15 & 0.07 & 5 & 2195.58 \\
\hline Time + Time ${ }^{2}+$ 10DayDrought + MaxTemp & 1.22 & 0.07 & 5 & 2195.65 \\
\hline Time + 10DayDrought + LagOver35C & 1.36 & 0.06 & 4 & 2197.78 \\
\hline Time + Time ${ }^{2}+$ 10DayDrought + MaxTemp + TotalPcp & 1.47 & 0.06 & 6 & 2193.89 \\
\hline Time + Time ${ }^{2}+10$ DayDrought + LagOver35C + TotalPcp & 1.47 & 0.06 & 6 & 2193.90 \\
\hline Time + 10DayDrought + LagOver35C + TotalPcp & 1.61 & 0.06 & 5 & 2196.03 \\
\hline Time + 10DayDrought + MaxTemp + MaxTemp ${ }^{\frac{1}{2}}$ & 1.83 & 0.05 & 5 & 2196.25 \\
\hline
\end{tabular}

The top ranked model included time-in-season (linear trend beginning 18 April ), daily precipitation (binary variable indicating drought occurrence, defined as $\geq 10$ consecutive days with $\leq 1 \mathrm{~mm}$ total rainfall), and daily maximum temperature $\left({ }^{\circ} \mathrm{C}\right)$. Lower ranked models included seasonal precipitation (total precipitation and number of days with $\geq 10 \mathrm{~mm}$ rain), an alternative maximum temperature variable (previous day's maximum $\geq 35^{\circ} \mathrm{C}$ ), and quadratic effects of time-in-season and maximum temperature.

therefore, there is no goodness-of-fit test implemented in Program MARK for nest survival models (Dinsmore et al. 2002, Rotella 2011).

\section{RESULTS}

Over the seven years of the study, we monitored the fate of 936 nests, ranging from 92 nests in 2001 to 215 nests in 2006. Only 35 nests were monitored in 2009 because of the specific study objective for this year. Average DNS was 0.956 (SE = 0.002 ), and nest success over the 29-day incubation period was $0.272(\mathrm{SE}=0.016)$. The earliest and latest days of nest activity from 2001-2009 were 18 April-6 August, with > 90\% of the nesting season occurring May-June.

Mountain Plover DNS was best predicted by time-in-season and daily weather conditions (Table 2) with higher survival rates early in the nesting season, during dry periods, and on cooler days (Fig. 2, Table 3). Daily precipitation effects were best modeled using droughts when $\geq 10$ days had passed with $\leq 1 \mathrm{~mm}$ total rainfall (10DayDrought), with strong positive effects of drought on DNS (Tables 2, 3, Appendix 2). Daily temperature effects were best modeled using daily maximum temperature (MaxTemp) or days when the previous afternoon's temperature exceeded $35^{\circ} \mathrm{C}$ (LagOver35C), with strong negative effects of heat on DNS. Daily minimum temperature (MinTemp) was correlated with time-in-season $(r=0.79)$; because time-in-season had a stronger effect on DNS than minimum temperature, we removed minimum temperature from the final analyses. Models containing minimum temperature instead of time had $\Delta \mathrm{AIC}_{c} \geq 7$ and weight $<0.004$ (Appendix 1).

Seasonal climate variables were not useful predictors of Mountain Plover DNS. The best seasonal precipitation variables were total precipitation (TotalPcp) and number of days with $\geq 10 \mathrm{~mm}$ rain (Days10mm). Both variables had weak negative effects on DNS (lower DNS in wetter seasons: Table 3) but did not improve upon the top-ranked model (Table 2). The best seasonal temperature variable, number of days with maximum temperature $\geq 32^{\circ} \mathrm{C}$ (DaysOver32C), appeared only in a model with $\Delta \mathrm{AIC}_{c}>45$ and weight near zero (Appendix 1).

Fig. 2. Daily nest survival of Mountain Plovers (Charadrius montanus) in eastern Colorado, 2001-2009, as a function of daily maximum temperature, drought, and time-in-season. Dry periods were defined as droughts in which $\geq 10$ consecutive days had $\leq 1 \mathrm{~mm}$ total precipitation, while wet periods had $>1 \mathrm{~mm}$ total precipitation. Days 21 (early $=8$ May) and 58 (late $=14$ June) were the $12.5 \%$ and $87.5 \%$ points in the nesting season and thus bound the middle $75 \%$ of nest activity. Nest survival over the entire nesting period $=(\text { daily nest survival })^{\wedge} 29$.

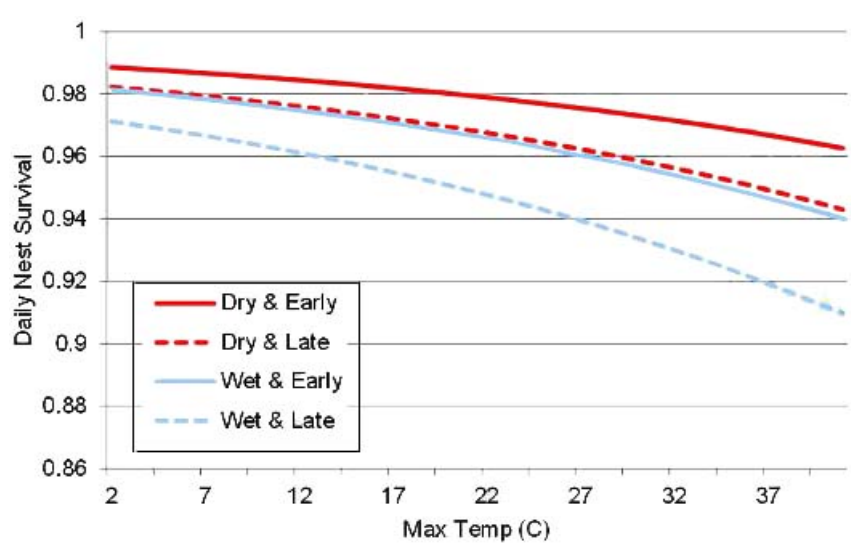


Table 3. Coefficient estimates for the top three models $(\triangle \mathrm{AICc}<1)$ with weights totaling 0.322 used to calculate the logit of daily nest survival probability of Mountain Plover (Charadrius montanus).

\begin{tabular}{|c|c|c|c|}
\hline Model & Variable & $\beta$ Estimate $\pm \mathrm{SE}$ & $95 \% \mathrm{CI}$ \\
\hline \multicolumn{4}{|c|}{ Time + 10DayDrought + MaxTemp } \\
\hline & Time & $-0.012 \pm 0.003$ & $(-0.019,-0.005)$ \\
\hline & 10DayDrought & $0.498 \pm 0.161$ & $(0.182,0.814)$ \\
\hline & MaxTemp & $-0.031 \pm 0.013$ & $(-0.056,-0.006)$ \\
\hline & Intercept & $4.276 \pm 0.293$ & $(3.703,4.850)$ \\
\hline \multicolumn{4}{|c|}{ Time + 10DayDrought + MaxTemp + TotalPcp } \\
\hline & Time & $-0.011 \pm 0.003$ & $(-0.018,-0.005)$ \\
\hline & 10DayDrought & $0.467 \pm 0.163$ & $(0.148,0.785)$ \\
\hline & MaxTemp & $-0.034 \pm 0.013$ & $(-0.059,-0.009)$ \\
\hline & TotalPcp & $-0.002 \pm 0.001$ & $(-0.005,0.001)$ \\
\hline & Intercept & $4.499 \pm 0.338$ & $(3.836,5.162)$ \\
\hline \multicolumn{4}{|c|}{ Time + 10DayDrought + MaxTemp + Days10mm } \\
\hline & Time & $-0.012 \pm 0.003$ & $(-0.018,-0.005)$ \\
\hline & 10DayDrought & $0.466 \pm 0.164$ & $(0.144,0.787)$ \\
\hline & MaxTemp & $-0.032 \pm 0.013$ & $(-0.057,-0.007)$ \\
\hline & Days $10 \mathrm{~mm}$ & $-0.030 \pm 0.029$ & $(-0.087,0.027)$ \\
\hline & Intercept & $4.368 \pm 0.307$ & $(3.765,4.970)$ \\
\hline
\end{tabular}

The top ranked models include a linear trend throughout the breeding season starting with 18 April (Time), $\geq 10$ consecutive days with $\leq 1 \mathrm{~mm}$ total rainfall (10DayDrought), daily maximum temperature $\left({ }^{\circ} \mathrm{C}\right.$; MaxTemp), total precipitation during May and June (mm; TotalPcp), and $\geq 10$ consecutive days with $\geq 10 \mathrm{~mm}$ precipitation (Days10mm). Coefficients for additional models are shown in Appendix 2.

For perspective on weather conditions during our study, $75.7 \%$ of days had no rainfall, droughts lasted up to 45 days, and droughts lasting at least 10 days occurred in each year of the study. Daily precipitation (Fig. 3) averaged $1.59 \pm 5.13 \mathrm{~mm}$ and ranged from $0-71.12 \mathrm{~mm}$ over all sites and years. Maximum temperature (Fig. 3) averaged $27.7 \pm 7.4^{\circ} \mathrm{C}$ and ranged from $2.2-41.1^{\circ} \mathrm{C} ; 18.4 \%$ of days exceeded $35^{\circ} \mathrm{C}$, occurring in late May-August. The earliest occurrence of a $35^{\circ}$ $\mathrm{C}$ day advanced monotonically during the study from 9 June in 2001 to 19 May in 2009.

\section{DISCUSSION}

Daily precipitation depressed nest survival of Mountain Plovers both in the core of the species' range in eastern Colorado (this study) and at the northern edge of their range in Montana (Dinsmore et al. 2002). The role of drought as an ecological driver of plover population recruitment is further supported by the correlation of annual survival of adult Mountain Plovers with dry climatic conditions (Dinsmore 2008) and drought-induced recruitment of young (Wunder 2007). The Colorado and Montana nest survival studies differed in the actual metric that best described the relationship; the best-fitting daily precipitation metric in our study was an extended lack of precipitation (droughts when $\geq$ 10 days had passed with $\leq 1 \mathrm{~mm}$ total rainfall), whereas Dinsmore et al. (2002) reported lower survival with rain events $\geq 2.54 \mathrm{~cm}$.
Fig. 3. Range of daily precipitation, maximum and minimum temperature values for eastern Colorado in 20012009. Wettest season: 2001. Driest season: 2002. Hottest season: 2002. Coldest season: 2003.

The effect of temperature on nest survival differed among studies, with cooler temperatures favoring nest survival of plovers in Colorado (this study) but no effect of temperature in Montana (Dinsmore et al. 2002). The inconsistency in the role of temperature between Colorado and Montana might be explained by the average breeding season temperatures in the two locales, with long-term average and maximum temperatures in our study area averaging higher than those near the study site of Dinsmore et al. (2002) in north central Montana by $1.9^{\circ} \mathrm{C}$ and $2.4^{\circ} \mathrm{C}$, respectively (www.wrcc.dri.edu/ COMPARATIVE.html). The higher temperatures in Colorado might expose plovers or their eggs to heat stress.

Precipitation and temperature likely influence the behavior of plovers, their prey, and their nest predators. Predation is the primary cause of nest failure across the range of the Mountain Plover and thus drives nest survival rates (Dinsmore et al. 2002, Dreitz and Knopf 2007). Higher nest mortality under wet conditions may result from higher activity levels and enhanced olfactory sensitivity of nest predators in wet than dry conditions (Dinsmore et al. 2002).

Climate change may exacerbate population declines in Mountain Plovers and result in shifts in distribution and changes in local abundance and fecundity. Temperatures across Colorado have increased by $1.1^{\circ} \mathrm{C}$ in the past 30 years, and continued warming of $2.2^{\circ} \mathrm{C}$ is expected by 2050 (Ray et al. 2008), potentially compromising nest survival. However, climate models for Colorado project seasonal shifts in precipitation with greater midwinter but decreased late spring and summer precipitation (Ray et al. 2008), potentially favoring nest survival. The frequency of extreme events such as droughts and intense rainstorms is predicted to increase, and the highly variable climate characterizing the Great Plains is projected to become even more variable (Ojima and Lackett 2002, Shortgrass Steppe Long Term Ecological Research 2010). Within the range of weather parameters recorded in this study, lower precipitation likely would favor Mountain Plover abundance and nest survival, but higher temperatures may apply negative selective pressures. Predicted increases in intense rain events, associated with lower nest survival of Mountain Plovers in Montana (Dinsmore et al. 2002), also may disfavor plover fecundity.

Changes in climate can modify aboveground vegetation structure and habitat suitability for prairie birds. Although one might presume that shortgrass prairie conditions may trend toward more extensive bare ground as temperatures and evapotranspiration rates rise and summer precipitation declines, recent evidence is to the contrary. Rather, as storm intensity increases, soil moisture and aboveground net primary productivity are predicted to increase, and proportional evaporative water loss to decrease, even if storms are separated by longer droughts (Knapp et al. 2008, Heisler-White et al. 2009).
Climate-related responses in breeding performance of Mountain Plovers likely result from direct effects on eggs, chicks, and adults, as well as indirect effects on vegetation structure, insect availability, and predator abundance and behavior. Nest survival is ultimately driven by factors affecting nest predators, such as coyote (Canis latrans), swift fox (Vulpes velox), and bull snake (Pituophis catenifer), and their alternate prey (Schmidt 1999). As climate variability increases across the Great Plains, investigations on how ambient temperature and rainfall affect predator activity levels and hunting efficiencies could provide insights into climate change impacts on bird communities.

Mountain Plovers have adapted to habitat fragmentation across prairie ecosystems by readily using agricultural fields for breeding activity (Knopf and Wunder 2006, Dreitz and Knopf 2007). Agriculture, defined as the production of livestock and crops for human food consumption, is the primary land use of prairie ecosystems in North America. Agricultural processes and mechanisms will also be impacted by climate change. Predicting the impacts of changes in prairie ecosystems produced by climate change and the associated changes in agricultural practices should also be considered when forecasting the response of Mountain Plover, or any species reliant on prairie ecosystems, to climate change.

Responses to this article can be read online at: http://www.ace-eco.org/vol7/iss1/art6/responses/

\section{Acknowledgments:}

We sincerely thank the private landowners throughout the eastern plains of Colorado who provided access to their lands. Numerous individuals assisted with collection of field data. Financial and logistical support was provided by the Colorado Division of Wildlife, Colorado Farm Bureau, Colorado Field Ornithologists, Lois Webster Fund of the Audubon Society of Greater Denver, Great Plains Landscape Conservation Cooperative of the U.S. Fish and Wildlife Service (USFWS), Neotropical Migratory Bird Conservation Act Grant (USFWS), U.S. Geological Survey, and U.S. Department of Agriculture (Forest Service). Weather data were provided by the Shortgrass Steppe Long Term Ecological Research group (SGS LTER), USDA Agricultural Research Service (ARS), and National Oceanic and Atmospheric Administration. The SGS LTER group is a partnership between Colorado State University, ARS, and U.S. Forest Service Pawnee National Grassland, with significant funding provided by the National Science Foundation LTER program (NSF Grant \# DEB 0217631 and DEB 0823405). A. A. Yackel Adams, B. S. Cade, S. J. Dinsmore, P. M. Lukacs, and G. C. White assisted with data analyses. H. Johnson and D. W. Tripp provided useful comments on early drafts of this manuscript. Any use of trade, 
firm, or product names is for descriptive purposes only and does not imply endorsement by the U.S. Government.

\section{LITERATURE CITED}

Akaike, H. 1973. Information theory as an extension of the maximum likelihood principle. Pages 267-281 in B. N. Petrov and F. Csaki, editors. Second International Symposium on Information Theory. Akademiai Kiado, Budapest, Hungary.

Askins, R. A., F. Chávez-Ramírez, B. C. Dale, C. A. Haas, J. R. Herkert, F. L. Knopf, and P. D. Vickery. 2007. Conservation of grassland birds in North America: understanding ecological processes in different regions. Ornithological Monographs 64:1-52.

Augustine, D. J. 2010. Spatial versus temporal variation in precipitation in a semiarid ecosystem. Landscape Ecology 25:913-925. http://dx.doi.org/10.1007/s10980-010-9469-y

Brennan, L. A., and W. P. Kuvlesky. 2005. North American grassland birds: an unfolding conservation crisis? Journal of Wildlife Management 69:1-13. http://dx.doi.org/10.2193/0022 -541X(2005)069<0001:NAGBAU>2.0.CO;2

Brockway, D. G., R. G. Gatewood, and R. B. Paris. 2002. Restoring fire as an ecological process in shortgrass prairie ecosystems: initial effects of prescribed burning during the dormant and growing seasons. Journal of Environmental Management 65:135-152. http://dx.doi.org/10.1006/jema.200 $\underline{2.0540}$

Burnham, K. P., and D. R. Anderson. 2002. Model selection and multimodel inference: a practical information-theoretic approach. Springer, New York, New York, USA.

Collins, S. L., R. L. Sinsabaugh, C. Crenshaw, L. Green, A. Porras-Alfaro, M. Stursova, and L. H. Zeglin. 2008. Pulse dynamics and microbial processes in aridland ecosystems. Journal of Ecology 96:413-420. http://dx.doi.org/10.1111/j.1 365-2745.2008.01362.x

Davis, S. K. 2005. Nest-site selection patterns and the influence of vegetation on nest survival of mixed-grass prairie passerines. Condor 107:605-616. http://dx.doi.org/10.1650/0 010-5422(2005)107[0605:NSPATI]2.0.CO;2

Dinsmore, S. J. 2008. Influence of drought on annual survival of the Mountain Plover in Montana. Condor 110:45-54. http: //dx.doi.org/10.1525/cond.2008.110.1.45

Dinsmore, S. J., G. C. White, and F. L. Knopf. 2002. Advanced techniques for modeling avian nest survival. Ecology 83:3476-3488. http://dx.doi.org/10.1890/0012-9658(2002)083 [3476:ATFMAN]2.0.CO;2

Dreitz, V. J., and F. L. Knopf. 2007. Mountain Plovers and the politics of research on private lands. BioScience 57:681-687. http://dx.doi.org/10.1641/B570808
George, T. L., A. C. Fowler, R. L. Knight, and L. C. McEwen. 1992. Impacts of a severe drought on grassland birds in western North Dakota. Ecological Applications 2:275-284. http://dx.d oi.org/10.2307/1941861

Grant, T. A., T. L. Shaffer, E. M. Madden, and P. J. Pietz. 2005. Time specific variation in passerine nest survival: new insights into old questions. Auk 122:661-672. http://dx.doi.or $\mathrm{g} / 10.1642 / 0004-8038(2005) 122[0661: T V I P N S] 2.0 . C O ; 2$

Graul, W. D. 1975. Breeding biology of the Mountain Plover. Wilson Bulletin 87:6-31.

Heisler-White, J. L., J. M. Blair, E. F. Kelly, K. Harmoney, and A. K. Knapp. 2009. Contingent productivity responses to more extreme rainfall regimes across a grassland biome. Global Change Biology 15:2894-2904. http://dx.doi.org/10.1 111/j.1365-2486.2009.01961.x

Knapp, A. K., C. Beier, D. D. Briske, A. T. Classen, Y. Luo, M. Reichstein, M. D. Smith, S. D. Smith, J. E. Bell, P. A. Fay, J. L. Heisler, S. W. Leavitt, R. Sherry, B. Smith, and E. Weng. 2008. Consequences of more extreme precipitation regimes for terrestrial ecosystems. BioScience 58:811-821. http://dx.d oi.org/10.1641/B580908

Knopf, F. L. 1994. Avian assemblages on altered grasslands. Studies in Avian Biology 15:247-257.

Knopf, F. L. 1996. Prairie legacies-birds. Pages 135-148 in F. B. Samson and F. L. Knopf, editors. Prairie conservation: preserving North America's most endangered ecosystem. Island Press, Washington, D.C., USA.

Knopf, F. L., and J. R. Rupert. 1996. Reproduction and movements of Mountain Plovers breeding in Colorado. Wilson Bulletin 108:28-35.

Knopf, F. L., and M. B. Wunder. 2006. Mountain Plover (Charadrius montanus) in A. Poole and F. Gill, editors. The birds of North America, Number 211. The Academy of Natural Sciences, Philadelphia, Pennsylvania, and the American Ornithologists' Union, Washington, D.C., USA. [online] URL: http://bna.birds.cornell.edu/bna/species/211/articles/ introduction

Knowles, C. J., and P. R. Knowles. 1984. Additional records of Mountain Plovers using prairie dog towns in Montana. Prairie Naturalist 16:183-186.

Knowles, C. J., C. J. Stoner, and S. P. Gieb. 1982. Selective use of black tailed prairie dog towns by Mountain Plovers. Condor 84:71-74. http://dx.doi.org/10.2307/1367824

Kuenning, R. R., and H. E. Kingery. 1998. Mountain Plover. Pages 170-171 in H. E. Kingery, editor. Colorado breeding bird atlas. Colorado Bird Atlas Partnership and Colorado Division of Wildlife, Denver, Colorado, USA. 
Lomolino, M. V., R. Channell, D. R. Perault, and G. A. Smith. 2001. Downsizing nature: anthropogenic dwarfing of species and ecosystems. Pages 223-243 in J. L. Lockwood and M. L. McKinney, editors. Biotic homogenization. Kluwer/Plenum Press, New York, New York, USA. http://dx.doi.org/10.1007 1978-1-4615-1261-5 11

Mabee, T. J. 1997. Using eggshell evidence to determine nest fate of shorebirds. Wilson Bulletin 109:307-313.

Matthews, J. H. 2008. Anthropogenic climate change in the Playa Lakes Joint Venture Region: understanding impacts, discerning trends, and developing responses. World Wildlife Fund, Corvallis, Oregon, USA.

Mettenbrink, C. W., V. J. Dreitz, and F. L. Knopf. 2006. Nest success of mountain plovers relative to anthropogenic edges in eastern Colorado. Southwestern Naturalist 51:191-196. http://dx.doi.org/10.1894/0038-4909(2006)51[191:NSOMPR] 2.0.CO;2

Morrison, S. A., and D. T. Bolger. 2002. Variation in a sparrow's reproductive success with rainfall: food and predator-mediated processes. Oecologia 133:315-324. http:// dx.doi.org/10.1007/s00442-002-1040-3

Ojima, D. S, and J. M. Lackett. 2002. Preparing for a changing climate: the potential consequences of climate variability and change - Central Great Plains. Central Great Plains Steering Committee and Assessment Team, Colorado State University, Fort Collins, Colorado, USA.

Pielke, R. A., and N. Doesken. 2008. Climate of the shortgrass steppe. Pages 14-29 in W. Lauenroth and I. Burke, editors. Ecology of the shortgrass steppe. Oxford University Press, New York, New York, USA.

Ray, A. J., J. J. Barsugli, and K. B. Averyt. 2008. Climate change in Colorado: a synthesis to support water resources management and adaptation. CU-NOAA Western Water Assessment, Boulder, Colorado, USA.

Rotella, J. 2011. Nest survival models. Chapter 17 in E. Cooch and G. White, editors. Program MARK: a gentle introduction. [online] URL: http://www.phidot.org/software/mark/docs/book/

Rotenberry, J. T., and J. A. Wiens. 1989. Reproductive biology of shrubsteppe passerine birds: geographical and temporal variation in clutch size, brood size, and fledging success. Condor 91:1-14. http://dx.doi.org/10.2307/1368142

Rotenberry, J. T., and J. A. Wiens. 1991. Weather and reproductive variation in shrubsteppe sparrows: a hierarchical analysis. Ecology 72:1325-1335. http://dx.doi.org/10.2307/19 $\underline{41105}$

Samson, F. B., F. L. Knopf, and W. R. Ostlie. 2004. Great Plains ecosystems: past, present, and future. Wildlife Society
Bulletin 32:6-15. http://dx.doi.org/10.2193/0091-7648(2004) 32[6:GPEPPA]2.0.CO;2

Schmidt, K. A. 1999. Foraging theory as a conceptual framework for studying nest predation. Oikos 85:151-160. http://dx.doi.org/10.2307/3546801

Shortgrass Steppe Long Term Ecological Research. 2010. SGS LTER Annual report 2010: activities and findings. SGS LTER, Colorado State University, Fort Collins, Colorado, USA. [online] URL: http://sgsiter.colostate.edu/pdfs/2010rprts-prps ls/2010FinalAR.pdf

Skagen, S. K., and A. A. Yackel Adams. 2012. Weather effects on avian breeding performance and implications of climate change. Ecological Applications. In press. http://dx.doi.org/1 $\underline{0.1890 / 11-0291.1}$

U.S. Fish and Wildlife Service (USFWS). 2003. Endangered and threatened wildlife and plants: withdrawal of the proposed rule to list the Mountain Plover as threatened. Federal Register 68(174):53083-53101.

U.S. Fish and Wildlife Service (USFWS). 2011. Endangered and threatened wildlife and plants: withdrawal of the proposed rule to list the Mountain Plover as threatened. Federal Register 76(92):27756-27799.

White, G. C, and K. P. Burnham. 1999. Program MARK: survival estimation from populations of marked animals. Bird Study 46(Supplement):120-138. http://dx.doi.org/10.1080/00 $\underline{063659909477239}$

Wunder, M. B. 2007. Geographic structure and dynamics in mountain plover. Dissertation. Colorado State University, Fort Collins, Colorado, USA. 
APPENDIX 1. Nest survival models for Mountain Plover (Charadrius montanus). We ran 94 models with minimum $\mathrm{AICc}=2204.431$ for the model set. All models contain an intercept.

\begin{tabular}{|c|c|c|c|c|}
\hline Model & $\Delta \mathrm{AIC}_{c}$ & $w_{i}$ & $K$ & Deviance \\
\hline Time + 10DayDrought + MaxTemp & 0 & 0.126 & 4 & 2196.426 \\
\hline Time + 10DayDrought + MaxTemp + TotalPcp & 0.133 & 0.118 & 5 & 2194.557 \\
\hline Time + 10DayDrought + MaxTemp + Days10mm & 0.961 & 0.078 & 5 & 2195.386 \\
\hline Time + Time $^{2}+$ 10DayDrought + LagOver35C & 1.152 & 0.071 & 5 & 2195.577 \\
\hline Time + Time ${ }^{2}+10$ DayDrought + MaxTemp & 1.223 & 0.068 & 5 & 2195.648 \\
\hline Time + 10DayDrought + LagOver35C & 1.357 & 0.064 & 4 & 2197.783 \\
\hline Time + Time $^{2}+$ 10DayDrought + MaxTemp + TotalPcp & 1.468 & 0.061 & 6 & 2193.890 \\
\hline Time + Time $^{2}+10$ DayDrought + LagOver35C + TotalPcp & 1.474 & 0.060 & 6 & 2193.895 \\
\hline Time +10 DayDrought + LagOver35C + TotalPcp & 1.608 & 0.056 & 5 & 2196.032 \\
\hline Time + 10DayDrought + MaxTemp + MaxTemp ${ }^{2}$ & 1.826 & 0.051 & 5 & 2196.250 \\
\hline Time + Time $^{2}+$ 10DayDrought + MaxTemp + Days 10mm & 2.231 & 0.041 & 6 & 2194.653 \\
\hline Time + Time $^{2}+10$ DayDrought + LagOver35C + Days $10 \mathrm{~mm}$ & 2.389 & 0.038 & 6 & 2194.811 \\
\hline Time + 10DayDrought + LagOver35C + Days10mm & 2.539 & 0.035 & 5 & 2196.963 \\
\hline Time + Time $^{2}+$ 10DayDrought + MaxTemp + MaxTemp ${ }^{2}$ & 3.206 & 0.025 & 6 & 2195.628 \\
\hline Time + 10DayDrought & 4.369 & 0.014 & 3 & 2202.798 \\
\hline Time + Time $^{2}+10$ DayDrought & 4.903 & 0.011 & 4 & 2201.330 \\
\hline Time + Lag10DDrought & 5.371 & 0.009 & 3 & 2203.799 \\
\hline Time + 10DayDrought + TotalPcp & 5.570 & 0.008 & 4 & 2201.996 \\
\hline Time + 10DayDrought + Days10mm & 5.683 & 0.007 & 4 & 2202.110 \\
\hline Time + Time $^{2}+$ Lag10DDrought & 5.737 & 0.007 & 4 & 2202.163 \\
\hline Time + Time $^{2}+10$ DayDrought + TotalPcp & 6.190 & 0.006 & 5 & 2200.614 \\
\hline Time + Time ${ }^{2}+10$ DayDrought + Days $10 \mathrm{~mm}$ & 6.262 & 0.006 & 5 & 2200.687 \\
\hline Time + Time $^{2}+$ LagOver35C & 6.890 & 0.004 & 4 & 2203.317 \\
\hline MinTemp + 10DayDrought & 6.987 & 0.004 & 3 & 2205.415 \\
\hline Time + 10DayDrought + TotalPcp + TotalPcp ${ }^{2}$ & 7.036 & 0.004 & 5 & 2201.460 \\
\hline Time + 10DayDrought + Days10mm + Days10 $\mathrm{mm}^{2}$ & 7.685 & 0.003 & 5 & 2202.110 \\
\hline Time + Time $^{2}+10$ DayDrought + TotalPcp + TotalPcp $^{2}$ & 7.690 & 0.003 & 6 & 2200.112 \\
\hline MinTemp + Lag10DDrought & 8.035 & 0.002 & 3 & 2206.463 \\
\hline Time + Time $^{2}+10$ DayDrought + Days $10 \mathrm{~mm}+$ Days $10 \mathrm{~mm}^{2}$ & 8.256 & 0.002 & 6 & 2200.678 \\
\hline Time + LagOver35C & 8.347 & 0.002 & 3 & 2206.775 \\
\hline MinTemp + MinTemp² + 10DayDrought & 8.462 & 0.002 & 4 & 2204.889 \\
\hline Time + Time $^{2}+$ MaxTemp & 8.586 & 0.002 & 4 & 2205.013 \\
\hline Time + MaxTemp & 8.643 & 0.002 & 3 & 2207.071 \\
\hline Time + Time $^{2}$ & 8.792 & 0.002 & 3 & 2207.220 \\
\hline Time + Time $^{2}+$ Days $10 \mathrm{~mm}$ & 9.013 & 0.001 & 4 & 2205.439 \\
\hline Time + Time $^{2}+$ TotalPcp & 9.121 & 0.001 & 4 & 2205.548 \\
\hline Time + Days10mm & 9.264 & 0.001 & 3 & 2207.692 \\
\hline Time + TotalPcp & 9.284 & 0.001 & 3 & 2207.712 \\
\hline Time & 9.287 & 0.001 & 2 & 2209.716 \\
\hline MinTemp + MinTemp ${ }^{2}+$ Lag10DDrought & 9.558 & 0.001 & 4 & 2205.985 \\
\hline Time + Days $32 \mathrm{C}$ & 11.003 & 0.001 & 3 & 2209.431 \\
\hline Time +2001 to2003 & 11.241 & 0.000 & 3 & 2209.669 \\
\hline Time + AvgMax & 11.250 & 0.000 & 3 & 2209.678 \\
\hline MinTemp + Days10mm & 14.739 & 0.000 & 3 & 2213.167 \\
\hline MinTemp + 2001 to2003 & 15.023 & 0.000 & 3 & 2213.451 \\
\hline MinTemp & 15.026 & 0.000 & 2 & 2215.456 \\
\hline
\end{tabular}




\begin{tabular}{|c|c|c|c|c|}
\hline MinTemp + TotalPcp & 15.424 & 0.000 & 3 & 2213.852 \\
\hline MinTemp + AvgMax & 15.500 & 0.000 & 3 & 2213.929 \\
\hline MinTemp + Days32C & 15.585 & 0.000 & 3 & 2214.013 \\
\hline MinTemp + MinTemp ${ }^{2}$ & 16.645 & 0.000 & 3 & 2215.073 \\
\hline LagMinTemp & 17.833 & 0.000 & 2 & 2218.262 \\
\hline MeanTemp & 17.935 & 0.000 & 2 & 2218.364 \\
\hline LagMeanTemp & 22.311 & 0.000 & 2 & 2222.741 \\
\hline MaxTemp & 25.673 & 0.000 & 2 & 2226.103 \\
\hline LagOver35C & 26.103 & 0.000 & 2 & 2226.533 \\
\hline Under4C & 27.355 & 0.000 & 2 & 2227.784 \\
\hline LagOver32C & 27.858 & 0.000 & 2 & 2228.287 \\
\hline Over32C & 29.051 & 0.000 & 2 & 2229.480 \\
\hline LagMaxTemp & 30.110 & 0.000 & 2 & 2230.539 \\
\hline LagUnder4C & 32.887 & 0.000 & 2 & 2233.317 \\
\hline Over29C & 33.235 & 0.000 & 2 & 2233.665 \\
\hline LagOver29C & 35.108 & 0.000 & 2 & 2235.538 \\
\hline 10DayDrought & 35.237 & 0.000 & 2 & 2235.667 \\
\hline Lag10DDrought & 36.640 & 0.000 & 2 & 2237.069 \\
\hline Lag7DDrought & 39.201 & 0.000 & 2 & 2239.630 \\
\hline 7DayDrought & 39.383 & 0.000 & 2 & 2239.812 \\
\hline Over35C & 39.426 & 0.000 & 2 & 2239.856 \\
\hline Under0C & 41.389 & 0.000 & 2 & 2241.819 \\
\hline LagUnder0C & 41.727 & 0.000 & 2 & 2242.157 \\
\hline Lag5DDrought & 41.730 & 0.000 & 2 & 2242.159 \\
\hline Days10mm & 41.866 & 0.000 & 2 & 2242.295 \\
\hline TotalPcp & 42.465 & 0.000 & 2 & 2242.894 \\
\hline 5DayDrought & 43.212 & 0.000 & 2 & 2243.641 \\
\hline Constant & 44.173 & 0.000 & 1 & 2246.603 \\
\hline Lag5mm & 44.436 & 0.000 & 2 & 2244.866 \\
\hline LagPrecip & 44.697 & 0.000 & 2 & 2245.126 \\
\hline Over5mm & 44.807 & 0.000 & 2 & 2245.236 \\
\hline Precip & 45.076 & 0.000 & 2 & 2245.506 \\
\hline Days32C & 45.183 & 0.000 & 2 & 2245.613 \\
\hline 2001to2003 & 45.240 & 0.000 & 2 & 2245.670 \\
\hline Lag10mm & 45.562 & 0.000 & 2 & 2245.992 \\
\hline AvgMax & 45.576 & 0.000 & 2 & 2246.006 \\
\hline Days35C & 45.588 & 0.000 & 2 & 2246.017 \\
\hline AvgMean & 45.606 & 0.000 & 2 & 2246.035 \\
\hline Days29C & 45.685 & 0.000 & 2 & 2246.115 \\
\hline AvgRange & 45.739 & 0.000 & 2 & 2246.169 \\
\hline Days4C & 45.901 & 0.000 & 2 & 2246.330 \\
\hline AvgMin & 45.901 & 0.000 & 2 & 2246.331 \\
\hline Days0C & 45.915 & 0.000 & 2 & 2246.344 \\
\hline $0 \mathrm{~mm}$ & 46.069 & 0.000 & 2 & 2246.498 \\
\hline LagTempRange & 46.075 & 0.000 & 2 & 2246.504 \\
\hline TempRange & 46.108 & 0.000 & 2 & 2246.537 \\
\hline Over10mm & 46.164 & 0.000 & 2 & 2246.593 \\
\hline Lag0mm & 46.173 & 0.000 & 2 & 2246.603 \\
\hline
\end{tabular}

Variables are defined in Table 1. 
APPENDIX 2. Coefficient estimates used to calculate the logit of daily nest survival probability for models with $\Delta \mathrm{AICc} \leq 2$ and weights $\geq 0.05$. Weights for these models total 0.753 .

\begin{tabular}{|c|c|c|c|}
\hline Model & Variable & $\beta$ Estimate \pm SE & $95 \% \mathrm{CI}$ \\
\hline \multicolumn{4}{|c|}{ Time + 10DayDrought + MaxTemp } \\
\hline & Time & $-0.012 \pm 0.003$ & $(-0.019,-0.005)$ \\
\hline & 10DayDrought & $0.498 \pm 0.161$ & $(0.182,0.814)$ \\
\hline & MaxTemp & $-0.031 \pm 0.013$ & $(-0.056,-0.006)$ \\
\hline & Intercept & $4.276 \pm 0.293$ & $(3.703,4.850)$ \\
\hline \multicolumn{4}{|c|}{ Time + 10DayDrought + MaxTemp + TotalPcp } \\
\hline & Time & $-0.011 \pm 0.003$ & $(-0.018,-0.005)$ \\
\hline & 10DayDrought & $0.467 \pm 0.163$ & $(0.148,0.785)$ \\
\hline & MaxTemp & $-0.034 \pm 0.013$ & $(-0.059,-0.009)$ \\
\hline & TotalPcp & $-0.002 \pm 0.001$ & $(-0.005,0.001)$ \\
\hline & Intercept & $4.499 \pm 0.338$ & $(3.836,5.162)$ \\
\hline \multicolumn{4}{|c|}{ Time + 10DayDrought + MaxTemp + Days10mm } \\
\hline & Time & $-0.012 \pm 0.003$ & $(-0.018,-0.005)$ \\
\hline & 10DayDrought & $0.466 \pm 0.164$ & $(0.144,0.787)$ \\
\hline & MaxTemp & $-0.032 \pm 0.013$ & $(-0.057,-0.007)$ \\
\hline & Days10mm & $-0.030 \pm 0.029$ & $(-0.087,0.027)$ \\
\hline & Intercept & $4.368 \pm 0.307$ & $(3.765,4.970)$ \\
\hline \multicolumn{4}{|c|}{ Time + Time $^{2}+10$ DayDrought + LagOver35C } \\
\hline & Time & $-0.032 \pm 0.014$ & $(-0.059,-0.005)$ \\
\hline & Time $^{2}$ & $0.0002 \pm 0.0001$ & $(-0.0001,0.0005)$ \\
\hline & 10DayDrought & $0.420 \pm 0.159$ & $(0.108,0.731)$ \\
\hline & LagOver35C & $-0.635 \pm 0.239$ & $(-1.102,-0.167)$ \\
\hline & Intercept & $3.943 \pm 0.306$ & $(3.343,4.543)$ \\
\hline \multicolumn{4}{|c|}{ Time + Time $^{2}+$ 10DayDrought + MaxTemp } \\
\hline & Time & $-0.024 \pm 0.014$ & $(-0.052,0.004)$ \\
\hline & Time $^{2}$ & $0.0001 \pm 0.0001$ & $(-0.0002,0.0004)$ \\
\hline & 10DayDrought & $0.475 \pm 0.163$ & $(0.155,0.795)$ \\
\hline & MaxTemp & $-0.030 \pm 0.013$ & $(-0.055,-0.005)$ \\
\hline & Intercept & $4.487 \pm 0.382$ & $(3.739,5.235)$ \\
\hline \multicolumn{4}{|c|}{ Time + 10DayDrought + LagOver35C } \\
\hline & Time & $-0.013 \pm 0.003$ & $(-0.020,-0.007)$ \\
\hline & 10DayDrought & $0.449 \pm 0.158$ & $(0.139,0.759)$ \\
\hline & LagOver35C & $-0.598 \pm 0.243$ & $(-1.073,-0.122)$ \\
\hline & Intercept & $3.553 \pm 0.141$ & $(3.277,3.829)$ \\
\hline \multicolumn{4}{|c|}{ Time + Time $^{2}+$ 10DayDrought + MaxTemp + TotalPcp } \\
\hline & Time & $-0.022 \pm 0.014$ & $(-0.050,0.005)$ \\
\hline & Time $^{2}$ & $0.0001 \pm 0.0001$ & $(-0.0002,0.0004)$ \\
\hline & 10DayDrought & $0.448 \pm 0.164$ & $(0.126,0.769)$ \\
\hline & MaxTemp & $-0.033 \pm 0.013$ & $(-0.058,-0.008)$ \\
\hline & TotalPcp & $-0.002 \pm 0.001$ & $(-0.005,0.001)$ \\
\hline & Intercept & $4.689 \pm 0.415$ & $(3.877,5.502)$ \\
\hline
\end{tabular}


Time + Time $^{2}+10$ DayDrought + LagOver $35 \mathrm{C}+$ TotalPcp

Time
Time $^{2}$
10DayDrought
LagOver35C
TotalPcp
Intercept

$$
\begin{array}{rc}
-0.031 \pm 0.014 & (-0.058,-0.005) \\
0.0002 \pm 0.0001 & (-0.0001,0.0005) \\
0.388 \pm 0.160 & (0.074,0.702) \\
-0.695 \pm 0.240 & (-1.165,-0.224) \\
-0.002 \pm 0.001 & (-0.005,0.001) \\
4.075 \pm 0.323 & (3.443,4.707)
\end{array}
$$

Time + 10DayDrought + LagOver35C + TotalPcp

$$
\begin{aligned}
& \text { Time } \\
& \text { 10DayDrought } \\
& \text { LagOver35C } \\
& \text { TotalPcp } \\
& \text { Intercept }
\end{aligned}
$$

$$
\begin{array}{rc}
-0.013 \pm 0.003 & (-0.019,-0.006) \\
0.415 \pm 0.160 & (0.101,0.728) \\
-0.660 \pm 0.244 & (-1.138,-0.182) \\
-0.002 \pm 0.001 & (-0.005,0.001) \\
3.695 \pm 0.177 & (3.347,4.043)
\end{array}
$$

Time + 10DayDrought + MaxTemp + MaxTemp ${ }^{2}$

$$
\begin{aligned}
& \text { Time } \\
& \text { 10DayDrought } \\
& \text { MaxTemp } \\
& \text { MaxTemp } \\
& \text { Intercept }
\end{aligned}
$$$$
-0.012 \pm 0.003
$$$$
(-0.019,-0.005)
$$$$
0.499 \pm 0.162
$$$$
(0.182,0.816)
$$$$
-0.071 \pm 0.099
$$$$
(-0.265,0.124)
$$$$
0.001 \pm 0.002
$$$$
(-0.003,0.004)
$$$$
4.774 \pm 1.277
$$

Variables are defined in Table 1. 